\title{
ANALISIS PENDAPATAN USAHA PETERNAKAN AYAM RAS PEDAGING POLA KEMITRAAN DAN NON KEMITRAAN DI KABUPATEN LAMONGAN
}

\author{
Novi Itsna Hidayati, SP.,MMA \\ Jurusan Agribisnis, Fakultas Pertanian Universitas Yudharta Pasuruan
}

\begin{abstract}
ABSTRAK
Efisiensi dalam usaha sangat menentukan keberhasilan pengelolaan usaha peternakan ayam ras pedaging agar mampu menghasilkan produk yang bias bersaing di pasar dan sekaligus membuka peluang kesempatan kerja serta memberikan pendapatan bagi peternak pola kemitraan dan mandiri.

Penelitian ini bertujuan untuk menganalisa perbedaan pendapatan ratarata, menganalisa alokasi faktor-faktor yang mempengaruhi produksi sekaligus tingkat efisien teknis, efisien harga dan efisien ekonomi usaha peternakan ayam ras pedaging pola kemitraan dan mandiri. Data yang digunakan adalah data produksi selama satu periode pemeliharaan seluruh usaha peternakan ayam ras pedaging pola kemitraan dan mandiri antara Desember 2014 - Februari 2015 di Kota Lamongan Jawa Timur. Model analisis yang digunakan adalah fungsi produksi Stochastic Frontier Cobb-Douglas.

Hasil penelitian ini menunjukkan bahwa berdasarkan uji beda t test peternak ayam ras pedaging mandiri memiliki tingkat pendapatan rata-rata yang berbeda dibandingkan peternak pola kemitraan, hal ini ditunjukkan dengan nilai R/C Ratio peternak mandiri sebesar 1,26 lebih tinggi dibanding peternak pola kemitraan yang hanya 1,06. Dalam hal ini peternak yang berusaha secara mandiri lebih menguntungkan daripada peternak pola kemitraan.

Hasil uji terhadap faktor produksi menunjukkan bahwa variable bibit ayam (DOC) dan pakan berpengaruh nyata (signifikan) pada $\alpha=1 \%$ dan berhubungan positif dengan produksi, dengan nilai koefisien yang cukup besar yang artinya bahwa pertambahan DOC atau pakan akan meningkatkan produksi, sedangkan variable obat-obatan juga berpengaruh nyata namun menunjukkan hubungan yang negative terhadap produksi yang artinya bahwa perlu adanya pembatasan penggunaan obat-obatan agar produksi bias optimal. Analisis efisiensi teknis yang dicapai peternak ayam ras pedaging secara keseluruhan adalah sebesar 0,868 . Selain dipengaruhi secara nyata oleh faktor produksi juga dipengaruhi oleh faktor social ekonomi dan secara nyata pada $\alpha=10 \%$ mempengaruhi efiaiensi teknis adalah tingkat umur peternak dimana peternak berusia muda memiliki tingkat produktivitas yang lebih tinggi maka akan menambah efisiensi teknis.
\end{abstract}

Kata Kunci: Ayam ras pedaging, tingkat pendapatan, efisiensi,

\section{PENDAHULUAN}

Agribisnis perunggasan nasional telah mengalami perkembangan yang sangat pesat sejak dekade 1960-an. Hingga saat ini perunggasan di Indonesia terutama ayam ras pedaging berkembang sesuai dengan kemajuan perunggasan global yang mengarah kepada sasaran mencapai tingkat efisiensi yang optimal, namun upaya pembangunan industry perunggasan 
tersebut masih menghadapi tantangan global yang mencakup kesiapan daya saing produk, utamanya bila dikaitkan dengan lemahnya kinerja penyediaan bahan baku pakan yang merupakan $60-7-\%$ dari biaya produksi karena sebagian besar masih sangat tergantung dari impor (Departemen Pertanian, 2008).

Ayam ras pedaging merupakan salah satu jenis komoditas ternak yang menghasilkan daging dan memiliki nilai ekonomi yang cukup potensial. Beternak ayam ras pedaging benar-benar memiliki keuntungan yang tidak dimiliki oleh ternak lainnya yaitu waktunya pendek, pertumbuhannya cepat juga menghasilkan kotoran yang mempunyai nilai dwiguna (Hartono, 1999).

Kabupaten Lamongan merupakan salah satu Kabupaten yang memiliki berbagai macam sumber daya yang bisa dikembangkan untuk meningkatkan peluang dan jumlah lapangan kerja, sehingga tingkat kesejahteraan masyarakat bias merata. Demi tercapainya tujuan tersebut, pemerintah harus mampu mengembangkan sector pertanian yang potensial dengan harapan bahwa sector tersebut mampu memberikan kontribusi bagi perekonomian dan juga memiliki nilai efisiensi yang tinggi sebagai usaha ekonomi yang produktif.

Sector Pertanian merupakan salah satu sector penyedia pangan utama untuk menopang pertumbuhan industry. Sampai saat ini pertanian memegang peranan penting dalam perekonomian masyarakat baik secara nasional maupun daerah. Subsector peternakan memberikan kontribusi terbesar ke dua setelah perikanan dapam pembentukan PDRB Kabupaten Lamongan. Mulai tahun 2007 sampai 2011 susektor peternakan memberikan kontribusi yang terus meningkat setiap tahunnya. Hal ini bias dilihat pada table 1.1. di bawah ini:

Tabel 1. PDRB Kabupaten Lamongan atas dasar harga konstan (Juta Rupiah)

\begin{tabular}{|l|r|r|r|r|r|}
\hline $\begin{array}{c}\text { Sektor } / \\
\text { subsektor }\end{array}$ & \multicolumn{1}{c|}{$\mathbf{2 0 0 7}$} & \multicolumn{1}{c|}{$\mathbf{2 0 0 8}$} & \multicolumn{1}{c|}{$\mathbf{2 0 0 9}$} & \multicolumn{1}{c|}{$\mathbf{2 0 1 0}$} & \multicolumn{1}{c|}{$\mathbf{2 0 1 1}$} \\
\hline Pertanian & $\mathbf{2 . 7 3 6 . 6 4 5 , 8 7}$ & $\mathbf{2 . 8 5 9 . 0 9 5 , 9 1}$ & $\mathbf{2 . 9 9 6 . 9 6 8 , 4 8}$ & $\mathbf{3 . 1 3 5 . 7 4 7 , 7 1}$ & $\mathbf{3 . 2 0 9 . 7 6 6 , 2 2}$ \\
\hline Bahan makanan & $1.749 .276,58$ & $1.799 .795,04$ & 1.852 .165 .53 & $1.899 .536,28$ & $1.838 .367,97$ \\
\hline Perkebunan & $62.327,91$ & $70.105,85$ & $74.665,04$ & $76.296,36$ & $82.569,45$ \\
\hline Peternakan & $83.502,30$ & $85.865,96$ & $89.286,30$ & $96.333,72$ & $104.577,42$ \\
\hline Kehutanan & $4.242,79$ & $4.325,75$ & $1.859,94$ & $1.224,57$ & $1.227,73$ \\
\hline Perikanan & $837.296,79$ & $899.003,31$ & $978.991,67$ & $1.062 .356,78$ & $1.183 .023,66$ \\
\hline PDRB & $\mathbf{5 . 1 2 9 . 1 3 9 , 7 5}$ & $\mathbf{5 . 4 4 8 . 1 4 5 , 7 0}$ & $\mathbf{5 . 7 9 2 . 0 9 5 , 1 0}$ & $\mathbf{6 . 1 9 1 . 0 6 6 , 4 8}$ & $\mathbf{6 . 6 2 5 . 8 2 3 , 0 3}$ \\
\hline
\end{tabular}


Pola kemitraan yang digunakan oleh peternak di Kabupaten Lamongan adalah pola kemitraan PIR (Perusahaan Inti Rakyat) pengunggasan, dimana peternak sebagai plasma hanya menyediakan tanah, kandang, peralatan, dan tenaga kerja, sedangkan perusahaan sebagai intinya menyediakan semua yang dibutuhkan peternak seperti DOC (Day Old Chick), pakan, obat-obatan, dan lainlain.

Peternak mandiri prinsipnya menyediakan seluruh input produksi dari modal sendiri dan bebas memasarkan produknya. Pengambilan keputusan mencakup kapan memulai beternak dan memanen ternaknya, serta seluruh keuntungan dan resiko ditanggung sepenuhnya oleh peternak (Supriyatna, 2006). Ada beberapa faktor yang menyebabkan usaha peternakan ayam ras pedaging tetap dikelola secara mandiri oleh sebagian besar penduduk di Kota Pasuruan yaitu: 1) pemeliharaannya cukup mudah; 2) waktu pemeliharaannya cukup singkat; 3) tingkat pengembalian modal relative cepat. Namun selain itu ada beberapa hal yang menjadi kendala yaitu: 1) sarana produksi kurang; 2) manajemen pemeliharaan peternak yang belum memadai; 3) modal relative terbatas; 4) resiko pemasaran cukup besar; 5) usahanya tergantung situasi dan cenderung spekulatif (assosiassi pengusaha perunggasan Kota Lamongan, 2014).

Pola kemitraan usaha peternakan ayam ras pedaging yang dilaksanakan dengan pola inti plasma, yaitu kemitraan antara peternak dengan perusahaan dimana peternak sebagai plasma dan perusahaan sebagai inti. Pada pola inti plasma kemitraan ayam ras pedaging yang berjalan selama ini, perusahaan menyediakan sarana produksi peternakan (sapronak) sedangkan plasma menyediakan kandang dan tenaga kerja.

Faktor pendorong peternak ikut pola kemitraan adalah tersedianya sarana produksi peternakan, tersedianya tenaga ahli, modal kerja dari inti, dan pemasaran terjamin. Akan tetapi ada beberapa hal yang menjadi kendala bagi peternak pola kemitraan yaitu rendahnya posisi tawar pihak plasma terhadap pihak inti, dan terkadang masih kurang transparan dalam menentukan harga baik input maupun output. Ketidakberdayaan plasma dalam mengontrol kualitas sapronak yang dibelinya menyebabkan kerugian bagi plasma. Pada perkembangannya perusahaan yang bermitra sebagai inti di Kota Pasuruan adalah PT Bintang Sejatera (afiliasi PT Charoen Pokhpand Indonesia) yang melaksanakan kemitraan pola kontrak harga. Pada kemitraan ini peternak secara individu melakukan perjanjian kerja sama 
dengan perusahaan dan sepakat untuk menanggung segala resiko kerugian, dimana harga sapronak dan harga jual sudah ditentukan oleh perusahaan.

Hingga saat ini pro dan kontra kehadiran pola kemitraan inti plasma masih sangat rentan terhadap perkembangan usaha ayam ras pedaging di Kota Pasuruan. Dengan masuknya pola kemitraan yang dilakukan oleh perusahaan peternakan menimbulkan kekhawatiran bagi pengusaha poultry shop dan peternak mandiri terhadap penguasaan pasar karena kehadiran perusahaan besar dengan modal kuat lalu membangun jaringan kemitraan inti plasma dan bermain di pasar yang sama. Hal ini dapat merugikan peternak mandiri yang telah merintis pasar sejak awal karena volume produksinya lebih banyak dengan harga yang lebih murah.

Dengan melihat besarnya usaha peternakan ayam ras pedaging di Kota Pasuruan, maka sangat menarik untuk dilakukan studi tentang bagaimana para peternak baik yang mandiri maupun kemitraan dalam mengalokasikan faktorfaktor produksi yang mereka miliki untuk memperoleh keuntungan usaha yang tinggi termasuk didalamnya pencapaian tingkat efisiensi.

\section{METODE PENELITIAN}

Penelitian ini dilakukan di Kabupaten Lamongan Jawa Timur. Pemilihan lokasi ini dilakukan secara sengaja (purposive) dengan pertimbanga bahwa Kecamatan Kejayan merupakan salah satu sentra produksi ayam ras pedaging yang berdekatan dengan Surabaya sebagai tujuan pasar utama. Penelitian ini dilakukan kurang lebih selama empat bulan mulai dari pra penelitian sampai selesai yaitu pada bulan april sampai Juli 2014. Berdasarkan teknik pengambilan sampel tersebut maka besarnya sampel pemilihan ini sebanyak 75 peternak

Data dikumpulkan melalui empat cara yaitu: 1) wawancara langsung, menggunakan kuisioner terstruktur yang telah disiapkan, 2) wawancara mendalam menggunakan daftar pertanyaan terbuka sebagai pedoman wawancara, 3) observasi untuk melihat kegiatan maupun hasil kegiatan agribisnis ayam ras pedaging yang telah biasa dilakukan oleh peternak, dan 4) dokumentasi.

Model analisa yang digunakan adalah : analisa pendapatan, $\mathrm{R} / \mathrm{C}$ ratio, analisa produksi dan analisa efisiensi. Analisa pendapatan digunakan untuk mengetahui seberapa besar tingkat pendapatan para peternak ayam ras pedaging. Pendapatan usaha ternak 
merupakan selisih antara penerimaan dan semua biaya, yang dapat dirumuskan sebagai berikut (Soekartawi,1995):

$\Pi=\mathrm{TR}-\mathrm{TC}$.

Dimana:

$\Pi=$ pendapatan usaha ternak

$\mathrm{TR}=$ total penerimaan

$\mathrm{TC}=$ total biaya

Dalam penelitian ini yang digunakan adalah fungsi Produksi Frontier Stokastik (StochasticProduction Frontier). Model ini akan memberikan gambaran tentang estimasi dan fungsi dari penerapan Stokastik Frontier dalam menganalisa tentang efisiensi usaha ayam ras pedaging. Secara umum fungsi Stochastic Production Frontier (SPF) dapat dinyatakan sebagai berikut (Aigner, et al. 1977):

$\mathrm{Y}=\mathrm{f}(\mathrm{Xi}, \beta) \exp \mathrm{Ei}$

Dimana : $\beta=$ parameter yang akan di taksir

$\mathrm{Xi}=$ input

$\varepsilon i=v i+u i($ error term)

Dalam penelitian ini model SPF yang digunakan adalah :

$\mathrm{Y}_{\text {it }}=\mathrm{X}_{\mathrm{it}} \beta+\left(\mathrm{V}_{\mathrm{it}}-\mathrm{U}_{\mathrm{it}}\right) ; \mathrm{i}=1, \ldots \ldots, \mathrm{N}, \mathrm{t}=$ $1, \ldots \ldots, \mathrm{T}$.

Dimana:

$\mathrm{Y}_{\mathrm{it}}=$ Produksi yang dihasilkan peternak ayam ras pedaging pada waktu $\mathrm{t}$.

$\mathrm{X}_{\mathrm{it}}=$ Input yang digunakan peternak ayam ras pedaging pada waktu $t$.

$\mathrm{B}=$ Parameter yang diestimasi
$\mathrm{V}_{\text {it }}=$ Variabel acak yang berkaitan dengan faktor-faktor eksternal dan sebarannya normal $\mathrm{N}$

$\mathrm{U}_{\mathrm{it}}=$ Variabel acak yang mempengaruhi tingkat inefisiensi teknis yang sebarannya truncated dan berkaitan dengan faktor-faktor internal $\mathrm{N}$

Untuk mendapatkan efisiensi teknis (TE) dari usaha ayam ras pedaging dapat dilakukan perhitungan sebagai berikut:

$\mathrm{TE}_{\mathrm{i}}=\mathrm{E}\left[\exp \left(-\mathrm{u}_{\mathrm{i}}\right) \mathrm{e}_{\mathrm{i}}\right]$

Dimana : $0 \leq \mathrm{TE}_{\mathrm{i}} \leq 1$

Model matematis fungsi produksi frontier stokastik untuk usaha peternakan ayam ras pedaging dalam penelitian ini adalah sebagai berikut:

$\mathrm{Y}=\beta_{0} * \mathrm{X}_{1}{ }^{\beta 1} * \mathrm{X}_{2}{ }^{\beta 2} * \mathrm{X}_{3}{ }^{\beta 3} * \mathrm{X}_{4}{ }^{\beta 4} * \mathrm{X}_{5}{ }^{\beta 5} *$ $\mathrm{X}_{6}{ }^{\beta 6} * \mathrm{X}_{7}^{\beta 7} * \mathrm{D}^{\beta 8} *(\mathrm{vi}-\mathrm{ui})$

Kemudian bentuk tersebut ditrasnformasikan ke dalam bentuk double $\log$ natural (Ln). penggunaan double log natural ini digunakan untuk mendekatkan skala data sehingga menghindarkan diri dari heteroskedastisitas dan parameter atau koefisien regresinya bias langsung di baca sebagai elastisitas. 
Selanjutnya model fungsi produksi berubah setelah diestimasi yaitu menjadi fungsi produksi frontier Cobb-Douglas. Secara matematis menjadi:

$$
\begin{aligned}
\operatorname{LnY}= & \beta_{0} * \beta_{1} \operatorname{LnX}_{1} * \beta_{2} \operatorname{LnX}_{2} * \beta_{3} \operatorname{LnX}_{3} * \\
& \beta_{4} \operatorname{LnX}_{4} * \beta_{5} \operatorname{LnX}_{5} * \beta_{6} \operatorname{LnX}_{6} * \\
& \beta_{7} \operatorname{LnX}_{7} * \beta_{8} \mathrm{D} *(\mathrm{vi}-\text { ui }) \ldots . .(3.6)
\end{aligned}
$$

Dimana:

$$
\begin{aligned}
\mathrm{Y}= & \text { Jumlah produksi ayam ras pedaging } \\
& (\mathrm{Kg}) \\
\mathrm{X}_{1}= & \text { Bibit ayam (DOC) (ekor) } \\
\mathrm{X}_{2}= & \text { Pakan }(\mathrm{Kg}) \\
\mathrm{X}_{3}= & \text { obat-obatan (gram) } \\
\mathrm{X}_{4}= & \text { Tenaga kerja (HKSP) } \\
\mathrm{X}_{5}= & \text { Listrik (kwh) } \\
\mathrm{X}_{6}= & \text { Bahan bakar (rupiah) } \\
\mathrm{X}_{7}= & \text { Luas kandang ( } \left.{ }^{2}\right) \\
\mathrm{D}= & \text { Variabel dummy, kemitraan }=1 \\
& \text { dan mandiri }=0 \\
\mathrm{Vi}= & \text { kesalahan yang dilakukan karena } \\
& \text { pengambilan secara acak } \\
\mathrm{Ui}= & \text { efek dari efisiensi teknis yang } \\
& \text { muncul }
\end{aligned}
$$

\section{Analisa efisiensi}

Menurut Soekartawi (2001) jika fungsi produksi yang digunakan adalah fungsi Cobb-Douglas, maka:

$$
\begin{aligned}
\mathrm{Y} & =\mathrm{AX}^{\mathrm{b}} \text { atau } \operatorname{Ln} \mathrm{Y} \\
& =\mathrm{Ln} \mathrm{A}+\mathrm{bLnX}
\end{aligned}
$$

Maka kondisi produk marginal adalah: $\Delta \mathrm{Y} / \Delta \mathrm{X}=\mathrm{b}$ (koefisien parameter elastisitas), selanjutnya nilai produk marginal (NPM) dapat ditulis:

$\mathrm{NPM}=(\mathrm{bY}$ Py) $/ \mathrm{X}$

Dimana $:$ NPM = nilai produk marginal

$\mathrm{b}=$ elastisitas produksi

$\mathrm{Y}=$ produksi

Py = harga produksi

$\mathrm{X}=$ jumlah faktor produksi $\mathrm{X}$

\section{Analisa efisiensi ekonomis}

Menurut Soekartawi (1994), efisiensi ekonomi merupakan hasil kali antara seluruh efisiensi teknis dengan efisiensi harga dari seluruh faktor input dan dapat tercapai apabila kedua efisiensi tercapai. Efisiensi ekonomi usaha ayam ras pedaging dapat dinyatakan sebagai berikut: $\mathrm{EE}=\mathrm{ET} * \mathrm{EH}$

Dimana $: \mathrm{EE}=$ Efisiensi Ekonomi

$$
\mathrm{ET}=\text { Efisiensi Teknik }
$$

$$
\mathrm{EH}=\text { Efisiensi Harga }
$$

\section{Uji Heteroskedastisitas}

Asumsi penting dari model regresi linear klasik adalah bahwa gangguan (disturbance) yang muncul dalam fungsi regresi populasi adalah homoskedastik, yaitu semua gangguan tadi mempunyai varians yang sama. Uji heteroskedastisitas dilakukan dengan menggunakan uji Park (Gujarati, 2003). Bentuk fungsi yang digunakan adalah $\mathrm{e}_{\mathrm{i}}^{2}$ sebagai pendekatan dan melakukan regresi berikut : 
$\ln \mathrm{e}_{\mathrm{i}}^{2}=\ln { }^{2}+\ln \mathrm{X}_{\mathrm{i}}+\mathrm{i}$

Jika ternyata signifikan (penting) secara statistik, maka data terdapat heteroskedastisitas, apabila ternyata tidak signifikan, bisa menerima asumsi homoskedastisitas.

\section{HASIL DAN PEMBAHASAN}

Deskripsi variabel-variabel usaha peternakan ayam ras pedaging pola kemitraan di Kota Pasuruan dapat dilihat pada tabel 2 berikut:

Tabel 2. DESKRIPSI VARIABEL USAHA PETERNAKAN AYAM RAS PEDAGING POLA KEMITRAAN (N=28)

\begin{tabular}{|c|l|r|r|r|r|r|}
\hline No & \multicolumn{1}{|c|}{ Variabel } & Mean & Min & Max & Std.Dev & \multicolumn{1}{c|}{$\begin{array}{c}\text { Mean } \\
\text { Value }\end{array}$} \\
\hline 1. & Produksi (kg) & $6.939,46$ & 3.797 & 12.962 & $2.469,75$ & 95.547 .748 \\
2. & Produksi (ekor) & $3.594,00$ & 2.400 & 5.635 & 955,19 & 95.547 .748 \\
3. & Bibit Ayam/DOC (ekor) & $3.673,14$ & 2.500 & 5.660 & 977,32 & 18.475 .912 \\
4. & Pakan (kg) & $11.914,29$ & 6.300 & 23.100 & $4.571,52$ & 68.162 .143 \\
5. & Vaksin, Obat, Vtmn (gr) & $6.296,43$ & 4.650 & 10.500 & $2.095,27$ & 1.151 .568 \\
6. & Tenaga Kerja (hksp) & 68,20 & 34 & 143 & 27,92 & 1.699 .289 \\
7. & Listrik (kwh) & 321,71 & 92 & 653 & 165,05 & 170.848 \\
8. & Lahan Bakar (Rp) & $518.133,93$ & 205.000 & 1.050 .000 & $192.330,57$ & 518.134 \\
9. & & 394,61 & 224 & 672 & 118,37 & 1.495 .609 \\
\hline
\end{tabular}

Sumber: data primer diolah, April 2015

Rata-rata produksi usaha peternak ayam ras pedaging pola kemitraan di Kota Lamongan sebesar $6.939,46 \mathrm{~kg}$ dengan nilai sebesar Rp. 95.547.748,-- dari sejumlah 21 peternak yang diteliti. Sedangkan rata-rata bibit sebesar 3.673,14 ekor dengan nilai sebesar Rp. 18.475.912,- lalu pakan sebesar 11.914,29 kg dengan nilai sebesar Rp. 68.162.143,- . Rata-rata vaksin,obat dan vitamin sebesar 6.296.43 gr dengan nilai Rp. 1.151.568,-.

Untuk tenaga kerja rata-rata peternak pola kemitraan menyelesaikan pekerjaannya dalam waktu 68,20 hksp dengan upah rata-rata Rp. 1.699.289,- lalu listrik dan bahan bakar yang digunakan rata-rata sebesar $321 \mathrm{kwh}$ dan Rp. 518.134,- dengan nilai sebesar Rp. 170.848,- dan Rp. 518.134,-. Sedangkan untuk luas kandang setiap peternak ratarata menggunakan kandang berukuran $394,61 \mathrm{~m}^{2}$ atau $0,11 \mathrm{~m}^{2}$ per ekor dengan biaya penyusutan kandang dan peralatan sebesar Rp. 1.495.609,-. 
Tabel 3. DESKRIPSI VARIABEL USAHA PETERNAKAN AYAM RAS PEDAGING MANDIRI (N=125)

\begin{tabular}{|c|c|c|c|c|c|c|}
\hline No & Variabel & Mean & Min & $\operatorname{Max}$ & Std.Dev & $\begin{array}{l}\text { Mean } \\
\text { Price }\end{array}$ \\
\hline 1. & Produksi (kg) & $2.525,07$ & 478 & 11.693 & $2.098,26$ & 36.275 .720 \\
\hline 2. & Produksi (ekor) & $2.289,00$ & 485 & 12.600 & $1.909,74$ & 36.275 .720 \\
\hline 3. & Bibit Ayam/DOC (ekor) & $2.419,20$ & 500 & 14.000 & $2.057,08$ & 11.852 .760 \\
\hline 4. & Pakan $(k g)$ & $3.741,20$ & 850 & 20.800 & $3.245,51$ & 15.242 .424 \\
\hline 5. & Vaksin, Obat, Vtmn (gr) & $5.615,20$ & 1.450 & 32.900 & $5.532,22$ & 924.684 \\
\hline 6. & Tenaga Kerja (hksp) Listrik & 38,37 & 23 & 175 & 24,33 & 927.575 \\
\hline 7. & $\begin{array}{l}(\mathrm{kwh}) \\
\mathrm{R}\end{array}$ & 71,93 & 10 & 525 & 70,83 & 47.985 \\
\hline 8. & $\begin{array}{l}\text { Bahan Bakar (Rp) } \\
\text { Luas Kandano }\left(\mathrm{m}^{2}\right)\end{array}$ & $336.212,00$ & 90.000 & 2.205 .000 & $279.453,15$ & 336.212 \\
\hline 9. & & 133,59 & 40 & 133,59 & 120,63 & 411.254 \\
\hline
\end{tabular}

Sumber: data primer diolah, April 2015

Demikian pula halnya dengan deskripsi rata-rata variabel produksi usaha peternak ayam ras pedaging mandiri di Kota Pasuruan dapat dilihat pada tabel 4.6. diatas. Untuk produksi rata-rata ayam ras pedaging sebesar 2.552,48 $\mathrm{kg}$ dengan nilai sebesar Rp. 36.275.720,- dari sejumlah 54 peternak yang diteliti. Sedangkan rata-rata bibit sebesar 2.419,20 ekor dengan nilai sebesar Rp.11.852.760,lalu pakan sebesar $3.741,20 \mathrm{~kg}$ dengan nilai sebesar Rp. 15.242.424,-. Rata-rata vaksin,obat dan vitamin sebesar 5.615,20 gr dengan nilai Rp. 924.684,-. Lalu untuk tenaga kerja rata-rata peternak menyelesaikan pekerjaannya dalam waktu 38,37 hksp dengan upah rata-rata Rp. 927.575,- lalu listrik dan bahan bakar yang digunakan rata-rata sebesar 71,93 kwh dan Rp. 336.212,- dengan nilai sebesar Rp.
47.985,-- dan Rp 336.212,-. Sedangkan untuk luas kandang setiap peternak ratarata menggunakan kandang berukuran $133,59 \mathrm{~m}^{2}$ atau $0,06 \mathrm{~m}^{2}$ per ekor dengan biaya penyusutan kandang dan peralatan sebesar Rp. 411.254,-.

\section{Analisis Pendapatan Usaha Peternak}

\section{Ayam Ras Pedaging}

Biaya yang keluar berkaitan dengan jumlah ayam yang dipelihara dinamakan biaya variabel. Dalam penelitian ini biaya variabel terdiri dari: biaya bibit ayam (DOC), pakan, vaksin, obat dan vitamin, tenaga kerja, listrik, dan bahan bakar, Sebagian besar biaya variabel dihabiskan untuk pakan yaitu hingga $70 \%$ dari total biaya terutama untuk peternak pola kemitraan (Rasyaf, 2008). 
Tabel 4. STRUKTUR BIAYA, PENERIMAAN DAN PENDAPATAN RATA-RATA USAHA PETERNAKAN AYAM RAS PEDAGING DI KOTA LAMONGAN

\begin{tabular}{|c|c|c|c|c|}
\hline Uraian & $\begin{array}{c}\text { Peternak Pola } \\
\text { Kemitraan }\end{array}$ & $\begin{array}{c}\text { Proporsi } \\
\%\end{array}$ & $\begin{array}{l}\text { Peternak } \\
\text { Mandiri }\end{array}$ & $\begin{array}{c}\text { Proporsi } \\
\%\end{array}$ \\
\hline $\begin{array}{l}\text { Penerimaan } \\
\text { Biaya Variabel: }\end{array}$ & 26.172.509 & & 15.776.000 & \\
\hline Bibit Ayam (DOC) Pakan & 5.030 .000 & 20,31 & 4.954 .800 & 39,70 \\
\hline Vaksin, Obat dan & $\begin{array}{r}18.215 .057 \\
315.441\end{array}$ & $\begin{array}{r}73,54 \\
1,27\end{array}$ & $\begin{array}{r}6.257 .520 \\
372.156\end{array}$ & $\begin{array}{r}50,13 \\
2,98\end{array}$ \\
\hline Vitamin Tenaga & & & & \\
\hline Kerja Listrik & 454.001 & 1,83 & 402.050 & 3,22 \\
\hline Bahan Bakar & 47.066 & 0,19 & 23.262 & 0,19 \\
\hline & 140.615 & 0,57 & 141.421 & 1,13 \\
\hline Biaya Tetap: Pemeliharaan & & & & \\
\hline Penyusutan Kandang dan & 161.893 & 0,65 & 166.562 & 1,33 \\
\hline Peralatan Penyusutan & 326.656 & 1,32 & 122.421 & 0,98 \\
\hline Tempat Makan dan Minum & 78.597 & 0,32 & 42.410 & 0,34 \\
\hline Total Biaya & 24.769.328 & 100 & 12.482 .602 & 100 \\
\hline Pendapatan (TR-TC) R/C & 1.403 .182 & & 3.293 .398 & \\
\hline Ratio & 1.06 & & 1.26 & \\
\hline Profit Margin & $5,363 \%$ & & $20,87 \%$ & \\
\hline Berat Ayam (Panen) Tingkat & $1,93 \mathrm{Kg}$ & & $1,10 \mathrm{Kg}$ & \\
\hline Kematian Periode Panen per & $2,16 \%$ & & $5,34 \%$ & \\
\hline Tahun & 5-6 Kali & & 7-8 Kali & \\
\hline
\end{tabular}

Sumber: Data diolah Mei 2015

Berdasarkan tabel 4. diatas, bahwa untuk setiap pemeliharaan 1000 ekor ayam ras pedaging peternak pola kemitraan dan mandiri proporsi biaya terbesarnya dialokasikan untuk pakan yaitu $73,54 \%$ atau dengan nilai Rp. 18.215.057 untuk peternak pola kemitraan dan $50,13 \%$ dengan nilai sebesar Rp. 6.257 .520 untuk peternak mandiri. Selanjutnya biaya terbesar kedua adalah biaya bibit
(DOC), peternak pola kemitraan sebesar 20,31\% dengan nilai Rp. 5.030.000,- dan peternak mandiri sebesar $39,70 \%$ dengan nilai Rp. 4.954.800,--

Proporsi biaya berikutnya adalah biaya tenaga kerja sebesar $1,83 \%$ dengan nilai sebesar Rp. 454.000,- untuk peternak kemitraan dan 3,22\% dengan nilai sebesar Rp. 402.050,- untuk peternak mandiri, selanjutnya vaksin, obat dan vitamin; 
bahan bakar serta yang terkecil adalah biaya listik dengan proporsi antara $0,19 \%$ 2,98\% . Proporsi terbesar untuk biaya tetap adalah biaya penyusutan kandang dan peralatan serta pemeliharaan peternak kemitraan dengan nilai Rp. 569.087,-dimana dalam satu tahun periode pemeliharaannya sebanyak 5-6 kali. Sedangkan untuk peternak mandiri biaya tetap sebesar Rp. 359.778,- dan dalam setahun sebanyak 7-8 kali periode pemeliharaan.

Berdasarkan perhitungan R/C Ratio dan profit margin untuk kedua pola usaha tersebut menunjukkan bahwa usaha ternak mandiri lebih menguntungkan bila dibandingkan dengan usaha ternak pola kemitraan, hal ini ditunjukkan dengan nilai
R/C Ratio sebesar 1,28 untuk mandiri dan 1,06 untuk pola kemitraan. Namun bila dilihat dari segi efisiensi usaha, sebenarnya kedua usaha ternak tersebut cukup menguntungkan karena nilai $\mathrm{R} / \mathrm{C}>1$, namun rendahnya pencapaian tersebut merupakan tanda bahwa usaha ternak ayam ras pedaging cukup rawan dalam arti bahwa tingkat resiko dan ketidakpastiannya sangat tinggi.

Selain itu profit margin usaha ternak pola kemitraan dan mandiri menunjukkan bahwa antara kedua usaha tersebut juga berbeda, dimana profit margin untuk usaha ternak mandiri lebih tinggi yaitu $20,87 \%$ dari total penerimaan, sedangkan usaha ternak pola kemitraan hanya sebesar $5,36 \%$ dari total penerimaan.

Tabel 5. UJI BEDA BIAYA, PENERIMAAN DAN PENDAPATAN RATA-RATA USAHA PETERNAKAN AYAM RAS PEDAGING POLA KEMITRAAN DAN MANDIRI DI KOTA LAMONGAN

\begin{tabular}{|l|c|l|}
\hline \multicolumn{1}{|c|}{ Uraian } & t hitung & \multicolumn{1}{c|}{ Keterangan } \\
\hline Penerimaan & $15,35^{*}$ & Nilai t tabel uji 2 arah \\
Biaya Variabel: & & $\mathrm{t}$ tabel $\alpha=5 \%$ \\
Bibit Ayam (DOC) Pakan & & $\mathrm{t}(0,05: 27)=2,052 \mathrm{t}(0,05: 124)=$ \\
Vaksin, Obat dan Vitamin & $3,35^{*}$ & 1,96 \\
Tenaga Kerja & $18,24^{*}$ & jadi: \\
Listrik & $4,30^{*}$ & $(2,052-1,96) / 2=0,046$ \\
Bahan Bakar & 1,77 & $\mathrm{t}$ tabel $=0,046+1,96$ \\
Biaya Tetap: & $5,19^{*}$ & $\mathbf{2 , 0 0 6}$ \\
Pemeliharaan & 0,11 & $\mathrm{t}$ tabel $\alpha=1 \%$ \\
Penyusutan Kandang dan & 0,25 & $\mathrm{t}(0,01: 27)=2,771$ \\
Peralatan & $16,25^{*}$ & $\mathrm{t}(0,01: 124)=2,576$ jadi: \\
Penyusutan Tempat Makan dan Minum & $15,16^{*}$ & $(2,771-2,576) / 2=0,097 \mathrm{t}$ tabel = $0,097+$ \\
Pendapatan (TR-TC) & $12,40^{*}$ & $2,576 \quad \mathbf{2 0 7 3}$ \\
& & \\
\end{tabular}

* nyata pada $\alpha=0,01$

Sumber: Data diolah 2015 
Berdasarkan tabel 5. dapat dilihat bahwa terdapat perbedaan yang nyata pada $\alpha=1 \%$ pada sebagian besar komponen penerimaan dan biaya usaha peternakan ayam ras pedaging pola kemitraan dan mandiri di Kota Palu, yaitu antara lain: bibit ayam(DOC); pakan; vaksin, obat dan vitamin; listrik; penyusutan kandang dan peralatan; serta penyusutan tempat makan dan minum. Adapun komponen biaya yang tidak berbeda nyata adalah: tenaga kerja; bahan bakar; dan biaya pemeliharaan. Secara keseluruhan antara usaha peternakan ayam ras pedaging pola kemitraan dan mandiri memiliki perbedaan pendapatan rata-rata berdasarkan hasil uji beda $t$ test yang signifikan (nyata) pada $\alpha=1 \%$ dengan nilai sebesar 12,40 , di mana nilai $t$ htung $>\mathrm{t}$ tabel, berarti menolak $\mathrm{H} 0$ dan menerima hipotesis $\mathrm{H}_{1}$.

\section{Multikolinearitas}

Multikolinearitas adalah situasi adanya korelasi antara variabel-variabel penjelas diantara satu dengan yang lainnya atau adanya hubungan yang sempurna antara beberapa atau semua variabel bebas (X) dalam model regresi yang digunakan. Jika terjadi multikolinearitas yang serius dalam model (koefisien korelasi > 0,8), maka pengaruh masing-masing variabel bebas $(\mathrm{X})$ terhadap variabel tidak bebas (Y) tidak dapat dipisahkan, sehingga estimasi yang diperoleh akan menyimpang (bias). jika dilihat dari korelasi antara regressor dari matriks koefisien korelasi (hasil regresi terlampir) dimana antara variabel independen hanya variabel $\mathrm{X}_{1}$ (Bibit) yang mempunyai korelasi cukup tinggi dengan variabel $\mathrm{X}_{8}$ (Dummy) dengan tingkat korelasi sebesar 0,654, karena nilainya tidak melebihi 0,8 maka bisa dikatakan bahwa variabel-variabel dalam penelitian ini tidak terjadi multikolinearitas yang serius.

\section{Tabel 6. Nilai F-Statistik dan $\mathbf{R}^{2}$ dari Auxiliary Regression}

\begin{tabular}{|c|c|c|c|c|c|}
\hline Keterangan & $\begin{array}{l}\text { Variabel } \\
\text { Dependen }\end{array}$ & \multicolumn{2}{|l|}{ Variabel Independen } & F-Stat & Nilai $\mathrm{R}^{2}$ \\
\hline Model Awal & $\mathrm{Y}$ & \multicolumn{2}{|c|}{$\mathrm{X} 1, \mathrm{X} 2, \mathrm{X} 3, \mathrm{X} 4, \mathrm{X} 5, \mathrm{X} 6, \mathrm{X} 7, \mathrm{X} 8 \mathrm{D}$} & $3368,62 *$ & 0,995 \\
\hline Aux.Regression 1 & $\mathrm{X} 1$ & $\mathrm{X} 2, \mathrm{X} 3, \mathrm{X} 4, \mathrm{X} 5, \mathrm{X} 6, \mathrm{X} 7$ & $\mathrm{X} 8 \mathrm{D}$ & $710,79 *$ & 0,972 \\
\hline Aux.Regression 2 & $\mathrm{X} 2$ & $\mathrm{X} 1, \mathrm{X} 3, \mathrm{X} 4, \mathrm{X} 5, \mathrm{X} 6, \mathrm{X} 7$ & X8D & $243,97 *$ & 0,922 \\
\hline Aux.Regression 3 & $\mathrm{X} 3$ & $\mathrm{X} 1, \mathrm{X} 3, \mathrm{X} 4, \mathrm{X} 5, \mathrm{X} 6, \mathrm{X} 7$ & X8D & $209,37 *$ & 0,910 \\
\hline Aux.Regression 4 & $\mathrm{X} 4$ & $\mathrm{X} 1, \mathrm{X} 2, \mathrm{X} 3, \mathrm{X} 5, \mathrm{X} 6, \mathrm{X} 7$ & $\mathrm{X} 8 \mathrm{D}$ & $108,76^{*}$ & 0,840 \\
\hline Aux.Regression 5 & X5 & $\mathrm{X} 1, \mathrm{X} 2, \mathrm{X} 3, \mathrm{X} 4, \mathrm{X} 6, \mathrm{X} 7$ & $\mathrm{X} 8 \mathrm{D}$ & $63,29 *$ & 0,753 \\
\hline Aux.Regression 6 & X6 & $\mathrm{X} 1, \mathrm{X} 2, \mathrm{X} 3, \mathrm{X} 4, \mathrm{X} 5, \mathrm{X} 7$ & $\mathrm{X} 8 \mathrm{D}$ & $196,50 *$ & 0,905 \\
\hline Aux.Regression 7 & $\mathrm{X} 7$ & $\mathrm{X} 1, \mathrm{X} 2, \mathrm{X} 3, \mathrm{X} 4, \mathrm{X} 5, \mathrm{X} 6, \mathrm{Y}$ & & $160,23 *$ & 0,886 \\
\hline
\end{tabular}

Sumber: hasil regresi 
Berdasarkan hasil pada tabel 6. di mana hasil pengujian $\mathrm{F}$ tabel terhadap $\mathrm{F}$ hitung dari auxiliary regression seluruhnya signifikan karena F-hitung > Ftabel dimana nilai F-tabel sebesar 2,97. Dengan demikian dapat dinyatakan bahwa hasil estimasi untuk fungsi produksi CobbDouglas usaha ternak ayam ras pedaging terjadi pelanggaran multikolinieritas. Selanjutnya berdasarkan Klien's Rule of Thumb multikolinieritas yang terjadi tidak dianggap serius, hal ini disebabkan karena nilai $\mathrm{R}_{2}$ model fungsi $\mathrm{CD}$ adalah 0,995 masih lebih besar dari nilai $\mathrm{R}_{2}$ dari masing-masing auxiliary regression yang ada yaitu: 0,$983 ; 0,974 ; 0,863 ; 0,756$; 0,$824 ; 0,818$; dan 0,976 .

\section{Heterokedastisitas}

Hasil pengujian dengan menggunakan metode Park dapat dilihat pada tabel 7. berikut:

Tabel 7. Hasil Uji Heterokedastisitas Menggunakan Park Test

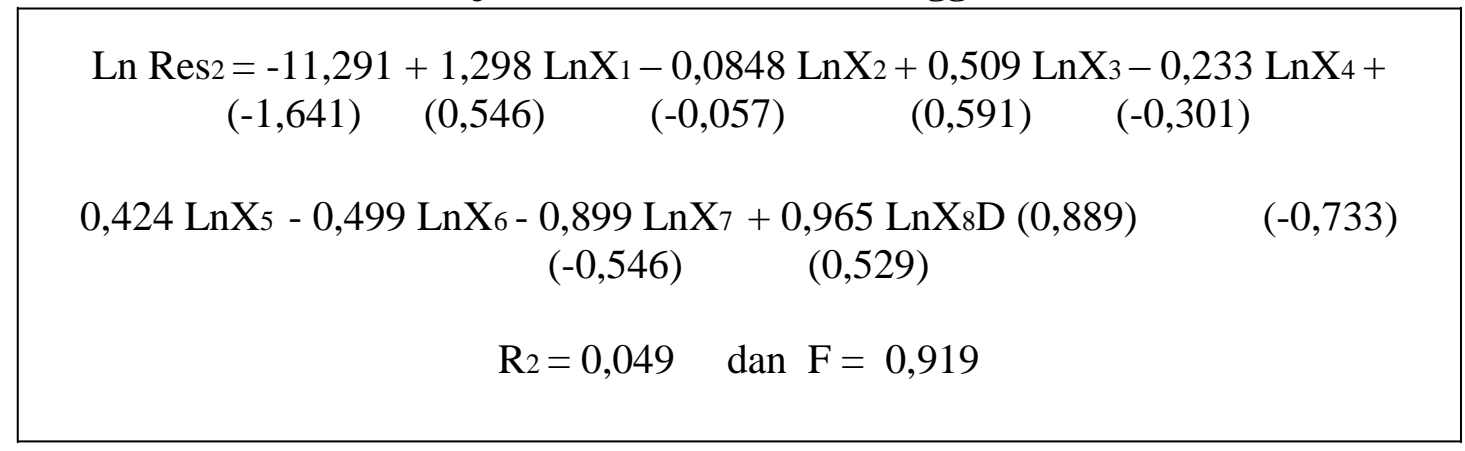

Dari hasil pengujian pada tabel 7 diatas menunjukkan bahwa semua variabel independen menunjukkan nilai $\beta$ yang tidak signifikan secara statistik pada $\alpha=$ 5\%. Sehingga dengan demikian hasil estimasi/regresi pada model Cobb-
Douglas usaha ternak ayam ras pedaging pada model bersifat homokedastisitas.

\section{Analisis Fungsi Produksi}

Hasil estimasi dari fungsi produksi frontier untuk usaha peternakan ayam ras pedaging dapat dilihat pada tabel 8 berikut: 
Tabel. 8. Estimasi Maksimum Likelihood Fungsi Produksi Frontier Stokastik Usaha Peternakan Ayam Ras Pedaging Di Kota lamongan

\begin{tabular}{|c|c|c|c|c|}
\hline Variabel & Parameter & Koefisen & $\begin{array}{c}\text { Standar } \\
\text { Error }\end{array}$ & t-ratio \\
\hline \multicolumn{5}{|l|}{ Fungsi Produksi } \\
\hline Intersep & $\beta_{0}$ & 6,85277 & 0,42795 & 16,01273 \\
\hline Bibit Ayam & $\beta_{1}$ & 0,56299 & 0,05083 & $11,07695^{*}$ \\
\hline \multirow{2}{*}{ Pakan } & $\beta_{2}$ & 0,41345 & 0,03195 & $12,93846^{*}$ \\
\hline & $\beta_{3}$ & $-0,05185$ & 0,01847 & $-2,80735^{*}$ \\
\hline Vaksin, Obat, Vitamin & $\beta_{4}$ & 0,03431 & 0,01673 & $2,05065^{* *}$ \\
\hline Tenaga Kerja & $B_{5}$ & 0,00743 & 0,01042 & 0,71326 \\
\hline Listrik & & 0,03676 & 0,01459 & $2,51915^{* *}$ \\
\hline Bahan Bakar & $\begin{array}{l}\beta 6 \\
\beta 7\end{array}$ & 0,01440 & 0,03424 & 0,42055 \\
\hline $\begin{array}{l}\text { Luas Kandang } \\
\text { Dummy }\end{array}$ & $\beta 8$ & 0,19411 & 0,03846 & $5,04763^{*}$ \\
\hline $\begin{array}{l}\text { Sigma-squared } \\
\left(\sigma_{2 s}=\sigma_{2 v}+\sigma_{2}\right)\end{array}$ & $\sigma_{2}$ & & & \\
\hline Gamma u & $\gamma$ & 0,00233 & 0,00026 & 9,06558 \\
\hline$\left(\gamma=\sigma_{2 u}+\sigma_{2 s}\right)$ & & 0,41223 & 1,11437 & 0,36993 \\
\hline
\end{tabular}

Log likelihood function $\quad=246,78$

LR test of the one-sided error $=5,86$

* nyata pada $\alpha=0,01$

** nyata pada $\alpha=0,05$

*** nyata pada $\alpha=0,10$

Dari fungsi produksi usaha ternak ayam ras pedaging di Kota Pasuruan, bahwa modal merupakan faktor yang sangat penting dalam usaha untuk meningkatkan produksi untuk peternak pola kemitraan dan mandiri. Dimana faktor produksi yang pengaruhnya dominan adalah jumlah bibit ayam/DOC dan pakan. Selain sangat nyata (significant), nilai koefisien parameternya pun paling besar yaitu 0,413 dan 0,563 (nyata pada $\alpha=1 \%$ ). Hal ini berarti bahwa setiap penambahan 10 persen DOC, akan diikuti dengan kenaikan produksi sebesar 4,13 persen dan setiap penambahan 10 persen pakan akan diikuti oleh penambahan produksi sebesar 5,63 persen. Kenyataan dilapangan menunjukkan bahwa penambahan DOC dan pakan cukup elastis mempengaruhi kuantitas produksi, dan secara teoritis bahwa apabila inputinput produksi usaha ternak meningkat 
maka outputpun harus meningkat. Senada dengan penelitian Sumartini (2004) bahwa input bibit ayam (DOC) berhubungan positif dengan output usaha ternak ayam ras pedaging pola kemitraan dan mandiri. Sedangkan input pakan berhubungan negatif terhadap output usaha ternak pola kemitraan, tetapi berhubungan positif terhadap output usaha ternak mandiri.

\section{Analisis Efisiensi Teknis}

Rata-rata tingkat efisiensi teknis yang dicapai oleh usaha ternak ayam ras pedaging di lokasi penelitian adalah sebesar 0,86819 artinya bahwa secara keseluruhan rata-rata produktivitas yang dicapai oleh usaha peternakan ayam ras pedaging pola kemitraan dan mandiri di daerah penelitian adalah sebesar 87 persen dari frontier yakni produktifitas maksimum yang dapat system pengelolaan yang baik. Secara keseluruhan, tingkat efisiensi teknis usaha ternak ayam ras pedaging pola kemitraan dan mandiri di lokasi penelitian secara umum belum efisien dengan nilai rata-rata efisiensi teknis adalah sebesar 0,87 . Sehingga masih perlu adanya upaya-upaya dari peternak untuk mengalokasikan input-input secara lebih efisien, misalnya dengan mengurangi input vaksin, obat dan vitamin yang alokasinya memang sudah berlebih.

\section{Analisis Efisiensi Harga/Alokatif dan Efisiensi Ekonomis}

Sedangkan Efisiensi Ekonomi adalah merupakan hasil kali antara seluruh efisiensi teknis dengan efisiensi harga dari seluruh faktor input $(\mathrm{EE}=\mathrm{ET} \times \mathrm{EH})$. Apabila nilai EE > 1 maka dikatakan belum efisien. 
Tabel 9. NILAI EFISIENSI HARGA DAN EFISIENSI EKONOMIS USAHA

PETERNAKAN AYAM RAS PEDAGING POLA KEMITRAAN

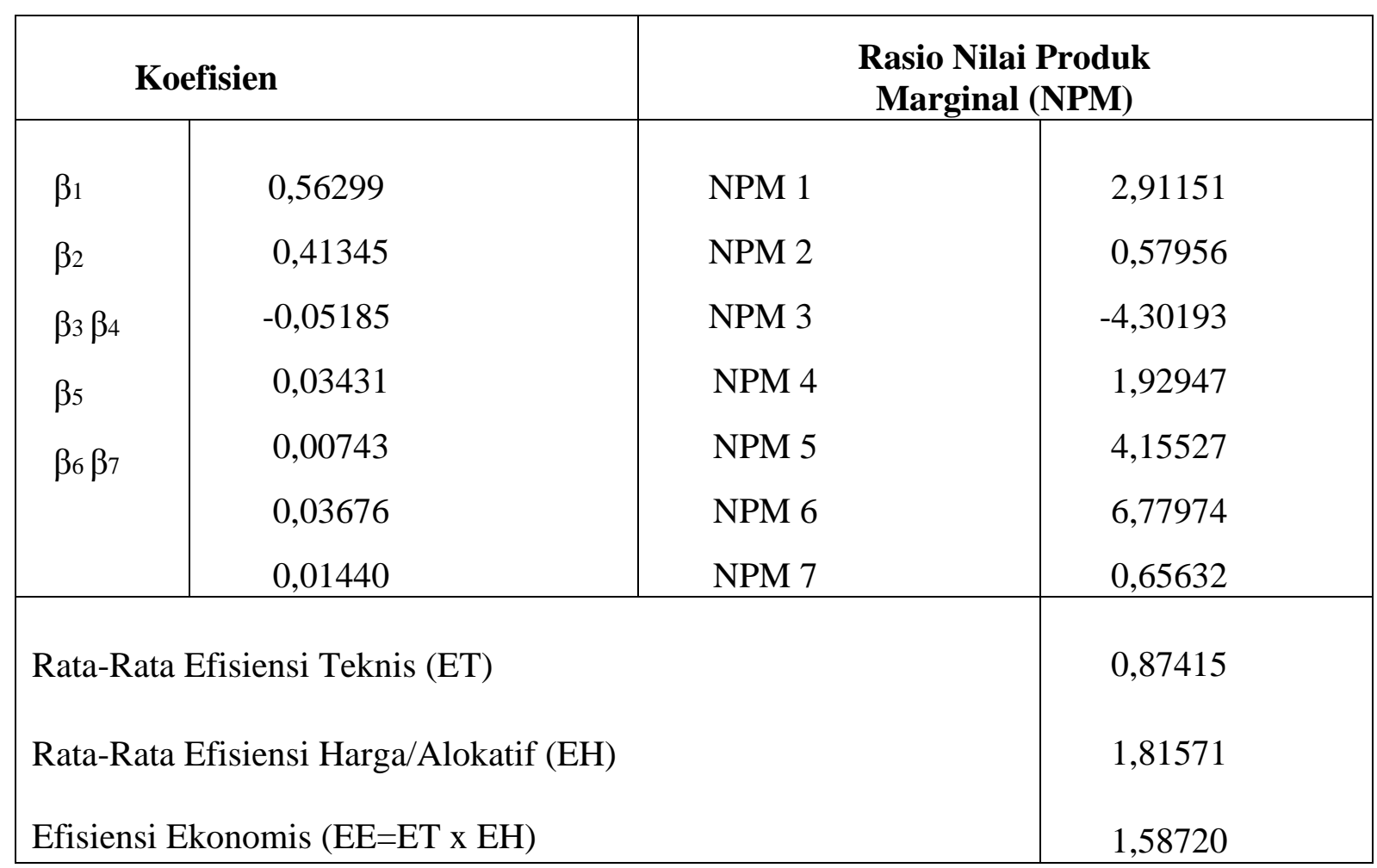

Hasil analisis alokasi efisiensi harga dan efisiensi ekonomis usaha peternakan ayam ras pedaging disajikan dalam tabel 9 untuk peternak pola kemitraan dan tabel 10 untuk peternak mandiri dimana variabel yang dianalisis adalah: bibit ayam/DOC $\left(\mathrm{X}_{1}\right)$, pakan $\left(\mathrm{X}_{1}\right)$, vaksin,obat dan vitamin $\left(\mathrm{X}_{3}\right)$, tenaga kerja $\left(\mathrm{X}_{4}\right)$, listrik $\left(\mathrm{X}_{5}\right)$, bahan bakar $\left(\mathrm{X}_{6}\right)$, dan penyusutan kandang dan peralatan $\left(\mathrm{X}_{7}\right)$. Data pada tabel 4.12. (Peternak Pola Kemitraan) menunjukkan bahwa rasio antara Nilai Produk Marginal (NPM) dari faktor produksi bibit ayam/DOC dengan harganya dalam satu periode pemeliharaan adalah 2,91 ( > 1). Hal itu menunjukkan bahwa secara ekonomis alokasi dari faktor produksi pada tingkat 3.673,14 ekor relatif masih belum efisien.

Secara keseluruhan pengalokasian dari ketujuh faktor produksi tersebut ternyata tidak satupun yang mencapai optimum. Hal tersebut ditunjukkan dari nilai rata-rata efisiensi harga yang juga lebih dari satu yaitu sebesar 1,82 dan efisiensi ekonomis yang merupakan hasil kali antara efisiensi teknis dan efisiensi harga nilainya juga sebesar 1,59 maka dapat disimpulkan bahwa usaha ternak 
ayam ras pedaging pola kemitraan di Kota Lamongan belum efisien.

Data pada tabel 10. (Efisiensi Harga dan Efisiensi Ekonomis Peternak Mandiri) dibawah ini menunjukkan bahwa rasio antara Nilai Produk Marginal (NPM) dari faktor produksi bibit ayam/DOC dengan harganya dalam satu periode pemeliharaan adalah 1,72 ( > 1). Hal itu menunjukkan bahwa secara ekonomis alokasi dari faktor produksi pada tingkat 2.419,20 ekor relatif masih belum efisien.

\section{Tabel 10. NILAI EFISIENSI HARGA DAN EFISIENSI EKONOMIS USAHA PETERNAKAN AYAM RAS PEDAGING MANDIRI}

\begin{tabular}{|l|c|c|c|}
\hline \multicolumn{2}{|c|}{ Koefisien } & \multicolumn{2}{c|}{$\begin{array}{c}\text { Rasio Nilai Produk } \\
\text { Marginal (NPM) }\end{array}$} \\
\hline$\beta_{1} \beta_{2} \beta_{3}$ & 0,56299 & NPM 1 & 1,72306 \\
$\beta 7$ & 0,41345 & NPM 2 & 0,98397 \\
& $-0,05185$ & NPM 3 & $-2,03402$ \\
& 0,03431 & NPM 4 & 1,34200 \\
& 0,00743 & NPM 5 & 5,61692 \\
& 0,03676 & NPM 6 & 3,96677 \\
& 0,01440 & NPM 7 & 1,27003 \\
\hline Rata-Rata Efisiensi Teknis (ET) & & 0,86647 \\
Rata-Rata Efisiensi Harga/Alokatif (EH) & & 1,83839 \\
Efisiensi Ekonomis (EE=ET x EH) & \multicolumn{3}{|l}{} \\
\hline
\end{tabular}

Sumber: data primer diolah,

Secara keseluruhan, dalam penelitian ini ditemukan bahwa baik usaha peternakan ayam ras pedaging pola kemitraan dan mandiri di lokasi penelitian belum efisien, baik efisiensi secara teknis, efisiensi harga/Alokatif dan efisiensi ekonomis yang nilai efisiensinya tidak sama dengan satu (1). Namun secara individual peternak pola kemitraan sedikit lebih efisien dari segi teknis bila dibandingkan dengan peternak mandiri.

\section{KESIMPULAN DAN SARAN}

\section{Kesimpulan}

Berdasarkan hasil analisis terhadap usaha peternakan ayam ras pedaging pola kemitraan dan mandiri di Kota Lamongan, maka dapat disimpulkan sebagai berikut:

1. Usaha peternakan ayam ras pedaging pola kemitraan dan mandiri di Kota Lamongan masih cukup menguntungkan, namun pendapatan 
rata-rata usaha ternak mandiri lebih besar dari rata-rata pendapatan usaha ternak pola kemitraan, hal ini terbukti dengan hasil uji beda t test.

2. Faktor-faktor/variabel yang berpengaruh nyata terhadap produksi adalah bibit ayam (DOC), pakan, tenaga kerja, dan bahan bakar, namun yang juga berpengaruh nyata namun tidak sesuai tanda adalah vaksin,obat dan vitamin. Listrik dan luas kandang walaupun tidak berpengaruh nyata namun menunjukkan tanda yang sesuai.

3. Rata-rata tingkat efisiensi teknis yang dicapai peternak ayam ras pedaging pola kemitraan dan mandiri sudah mencapai level yang cukup tinggi namun belum efisien dan masih memungkinkan untuk menambah variabel inputnya untuk mendapatkan hasil yang optimal.

\section{Saran}

1. Berkenaan dengan upaya peningkatan efisiensi dan produksi dari hasil usaha peternakan ayam ras pedaging di Kota Lamongan, dan mengingat bahwa efisiensi teknis yang dicapai oleh usaha peternakan baik yang dikelola oleh peternak pola kemitraan maupun peternak mandiri berada pada level yang cukup tinggi yaitu rata-rata diatas 0,8. Namun secara teknis diharapkan bagi peternak agar dapat mengalokasikan input-input produksinya lebih efisien lagi terutama dalam mengontrol penggunaan obat-obatan, khususnya pada usaha ternak mandiri.

2. Karena sebagian besar peternak mandiri di Kota Pasuruan merupakan peternak kecil dengan tingkat keterampilan yang rendah, serta masih lemah dalam manajemen, sehingga pemerintah melalui dinas terkait perlu menyiapkan tenaga ahli/pendamping lapangan yang bisa membimbing peternak.

3. Untuk lebih memberdayakan diri, peternak pola kemitraan harus mampu memanfaatkan ilmu pengetahuan dan teknologi yang mereka peroleh sebagai landasan untuk lebih memajukan usahanya dengan efisien, produktif dan professional serta berorientasi pada mutu yang sesuai dengan permintaan pasar.

\section{DAFTAR PUSTAKA}

Abrohim, Y. (2003). Studi Kelayakan Bisnis. Jakarta: Rineka Cipta

Akhdaryani, D. 2002. Analisis Keunggulan Komparatif Komoditas Andalan Utama Sektor Pertanian Jawa Timur Menjelang Perdagangan Global. 
Publikasi Ilmiah. Malang:

Universitas Brawijaya.

Direktorat Jenderal Peternakan. 2005. Infoeksekutif.

www.deptan.go.id/infoeksekutif/nak/ 2005.

Hafsah, M. J. 2000. Kemitraan Usaha, Konsep dan Strategi.Cetakan kedua. Jakarta:Penebar Swadaya.

Hartono, F. 1999. Beternak Ayam Pedaging Super. Pekalongan: Penerbit CV.Gunung Mas.

Husnan, \& Suwarsono, S. d. (2000). Studi Kelayakan Proyek. Yogyakarta: UUP AMP YKPN.

Saptana. 1999. Dampak Krisis Moneter dan Kebijakan Pemerintah Terhadap Profitabilitas dan Daya Saing Komoditas Ayam Ras di Bawa Barat. Tesis. Bogor: Institut Pertanian Bogor.

Siregar, M dan I Wayan Rusastra. 2003. Kebijakan Tarif Impor Paha Ayam dalam Melindungi Industri Perunggasan Nasional. Jurnal SOCA. Volume 3. Denpasar: Fakultas Pertanian Universitas Udayana.
Soejoedono,R. D., dan Ekowati Handaryani. 2005. Flu Burung. Jakarta: Penebar Swadaya.

Suparta, N. 2001. Perilaku Agribisnis dan Kebutuhan Peternak Ayam Ras Pedaging. Disertasi. Bogor: Institut Pertanian Bogor.

Suparta, N. 2005. Dampak Sosial dan Ekonomi bagi Peternak Unggas Pasca Flu Burung. Makalah disampaikan pada kegiatan Apresiasi Teknis Avian Influenza, yang diselenggarakan oleh Dinas Peternakan Propinsi Bali. Denpasar: 17 - 18 Nopember 2005.

Suparta, N. 2005. Pendekatan Holistik Membangun Agribisnis. Cetakan Pertama. Denpasar: CV.Bali Media Adhikarsa.

Zulaiha. 1997. Efisiensi Finansial, Efisiensi Ekonomi dan Pengaruh Kebijakan Pemerintah pada Penguasaan Teh Hijau di Jawa Barat dengan Pendekatan PAM. Skripsi. Bogor: Institut Pertanian Bogor. 